\title{
14. DOWNHOLE LOGGING AND LABORATORY PHYSICAL PROPERTIES MEASUREMENTS 1
}

\author{
I. A. Hill, Department of Geology, Leicester University \\ and \\ S. C. Cande, Lamont-Doherty Geological Observatory²
}

\begin{abstract}
During DSDP Leg 82 downhole logging experiments, the very poor hole conditions and technical failures that have affected earlier legs were absent. As a result, Holes 556, 558, and 564 were logged with a full suite of tools. In addition, nearly complete continuously cored sections were obtained at Sites 558 and 563, and these sections have been subjected to laboratory physical property measurements. The resulting data set allows a comparison of logged and laboratory measured values and correlation between holes.

The sediments encountered in all holes were calcareous oozes and chalks. Despite the lack of distinctive lithologies, changes in density and seismic velocity can be seen in both the laboratory and logged data and identified with sedimentologic features in the cores; the logged curves can be correlated between holes. Within basement rocks the logged curves provide information on the part of the formations not recovered by coring (about $55 \%$ ) and allow comparison between bulk properties and the sample properties measured in the laboratory. Comparison of the logged data with that from Site 417 shows systematic differences, perhaps related to crustal aging.
\end{abstract}

\section{INTRODUCTION}

The primary objective of DSDP Leg 82 was the sampling of igneous basement in a systematic pattern to the southwest of the Azores in order to look for geochemical anomalies. This resulted in a strategy of drilling many holes into basement as quickly as possible and washing through sediments as necessary. Downhole logging was to be used on any deep-penetration basement holes to provide information about the material not recovered by continuous coring. When holes are logged, the sediments are logged as well and it was hoped to partially compensate for the lack of sediment coring in this way.

Figure 1 shows actual pattern of the drill sites lying along flow lines and isochrons to the west of the spreading ridge. Partly fortuitously and perhaps partly a reflection of the physical state of the crust, all the deeppenetration holes lie on the oldest isochron, Magnetic Anomaly 13, aged $35 \mathrm{Ma}$. The exact depths of these holes and the depths of sediment and basement penetrated at each are shown in Figure 2. Holes 556, 558, and 564 were logged, whereas Holes 558 and 563 were cored through sediments as well as basement. The logging was remarkably successful by DSDP standards with a suite of logs including density, neutron, sonic, caliper, gamma-ray, and resistivity being run at each of the three holes and recording good quality data. Temperature logs were also run; the results are reported elsewhere (Hill and Cande, this volume). Basement core samples from the remaining holes were also used for laboratory measurements.

These measurements constitute one of the most complete sets of physical property data collected by a single

\footnotetext{
${ }^{1}$ Bougault, H., Cande, S. C., et al., Init. Repts. DSDP, 82: Washington (U.S. Govt. Printing Office).

2 Addresses: (Hill) Department of Geology, Leicester University, Leicester LE1 7RH, England; (Cande) Lamont-Doherty Geological Observatory, Palisades, NY 10964.
}

DSDP leg for both sediments and igneous crust of an extended region. This not only allows a reliable statement to be made about the formation of physical properties but allows comparison to be made between the log curves, the laboratory measurements, and the core descriptions. The high quality of the logging results also allows an examination of some of the problems of the unusual hole environment and its effect on the logging tool performance. Comparison can also be made with the results of previous logging in the Atlantic. The only data available at present is from Hole 417D, Legs 51, 52,53 , which has been fully reported by Salisbury et al. (1980). Because of operational difficulties, the Hole 417D data set was restricted to gamma-ray, resistivity, and sonic logs except for very restricted sections of the hole, but it does provide a useful comparative study with the present data. Hole 369B, Leg 46, was also logged successfully (Kirkpatrick, 1978) penetrating some $200 \mathrm{~m}$ into igneous basement. In the Pacific Ocean, logging data were obtained in the Gulf of California (Salisbury, 1983) where the crustal structure is very anomalous because of high sedimentation and in the Nauru Basin (Boyce, 1981) where $500 \mathrm{~m}$ of igneous basement were penetrated. The benchmark for DSDP logging experiments is Hole 504B, which has now been drilled and logged to over $1 \mathrm{~km}$ below the basement surface (Cann and Von Herzen, 1983; Anderson et al., 1982).

\section{DATA QUALITY}

The errors and inaccuracy in each data set must be checked before data interpretation can proceed. The laboratory measurements are relatively easy to check for error and accuracy, but their relevance to the actual physical conditions below the seabed before drilling disturbance and selective sampling are sometimes questionable. The logging tools measure properties in situ and are accurate within their design specifications, which may not include the particular hole conditions and li- 


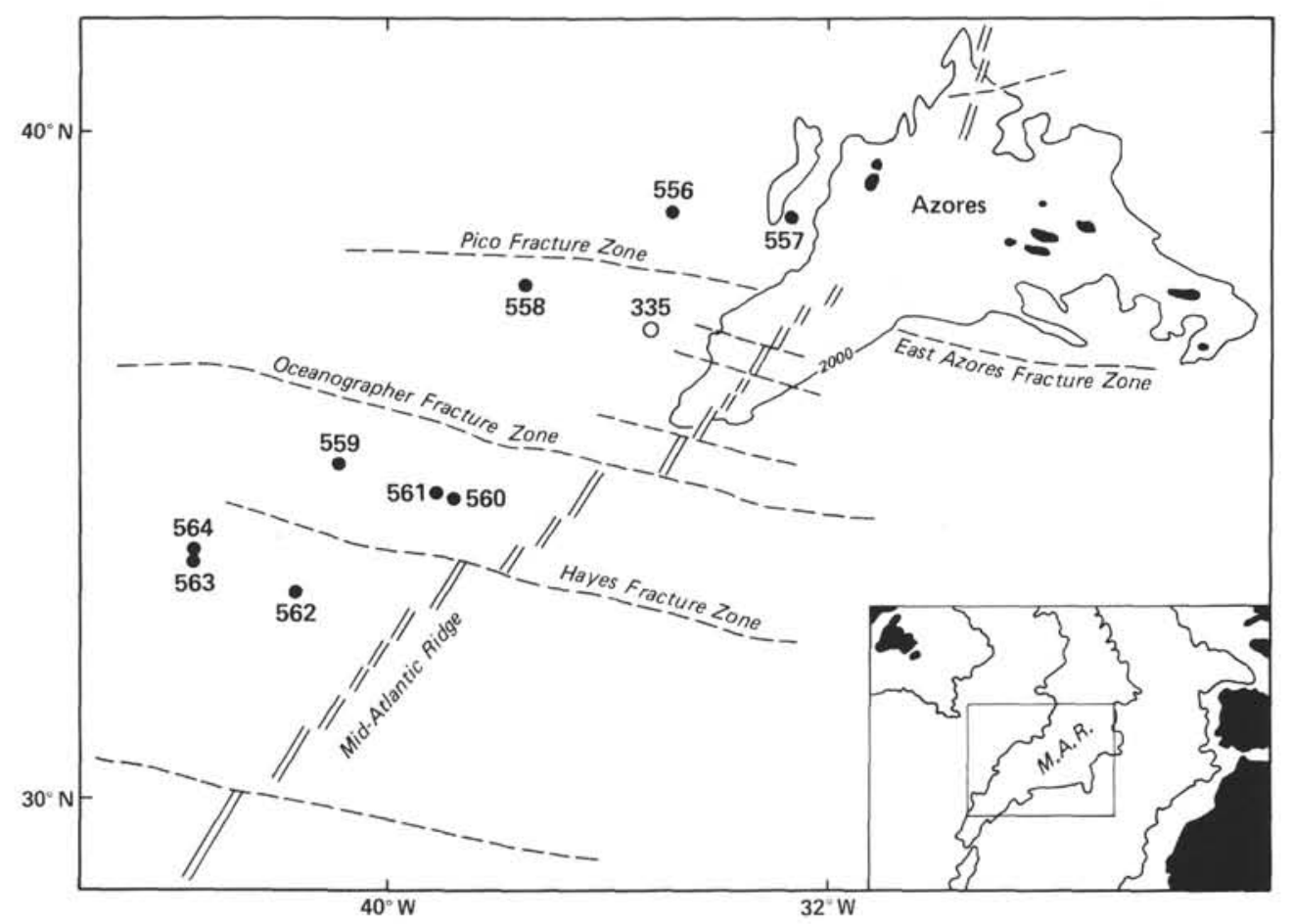

Figure 1. Location of Leg 82 drill sites.

thologies encountered in DSDP drilling. These problems will be reviewed below.

\section{Downhole Measurements}

All logging tools used during Leg 82 were of standard Schlumberger designs, optimized for use in mud-filled holes drilled through flat-lying, lithified, sedimentary strata. The contrasting conditions in DSDP holes is shown in Figure 3. The necessity to use the drill string as a casing into the top of the hole means that all tools must pass down the 4-in. diameter drill string cavity. This causes problems with sonic and caliper tools. Rubber pads designed to cushion impacts with the hole sidewall have to be removed to reduce the overall diameter of the tool. This results in more mechanical shock for the tool downhole and vibrations from these impacts add noise to sonic records. The drill string is safely located in the hole by extending it to $100 \mathrm{~m}$ sub-bottom depth. Few of the logging tools produce useful results when within the drillpipe and bottom hole assembly, hence the top part of any hole is inaccessible to logging.

Once within the open hole, soft sedimentary formations can become washed out by the circulating drilling water until the hole diameter exceeds the design limits of the tools. All the tools are designed and calibrated either to be operated along the axial centerline of the hole or to be held against the sidewall. Each of these modes of operation require the tool to possess arms that bear on the sidewall and physically locate the tool in the correct position. The maximum extension of the arms on different tools varies but is generally about $0.5 \mathrm{~m}$. When the hole diameter exceeds this limit, the tool swings freely in the hole and recorded data contains uncorrectable errors. Most of the arms make a potentiometric measure- ment of their extension as a caliper log, hence washed out hole conditions produce a maximum caliper reading with spurious irregular data values on the log curves. These features are well illustrated by the logged curves for Hole 558 (Fig. 4, back pocket). The drill pipe extends to about $96 \mathrm{~m}$ sub-bottom for sonic, resistivity, caliper, and gamma-ray measurements but was extended to $145 \mathrm{~m}$ sub-bottom while density and neutron porosity measurements were made. Above the end of the drill pipe there are no useful data from any tool. From 100 to about $185 \mathrm{~m}$ sub-bottom, the hole diameter is greater than the caliper extension, and the caliper reading is maximum, with noise spikes caused by bumping on the sidewall. The hole diameter is so large that the density and neutron porosity tools cannot be kept in contact with the sidewall and all values above $185 \mathrm{~m}$ sub-bottom from these particular tools are erroneous. The sonic and resistivity tools are less affected by the hole diameter, but the random noise on the dual laterolog (LLD) curve becomes much less when the hole diameter decreases so that the tool can be positively located along the centerline of the hole where it is designed to operate.

Confirmation of the absolute calibration of data values is also problematic. If individual tools are calibrated for a known response in specifically chosen test rock lithologies, corrections may then be necessary for ambient hole conditions of temperature and pressure, for the properties of the hole fluid and hole diameter, and for the differing physical response of the sidewall rock lithology compared to that calibration. Corrections for these effects are largely empirical but are fairly well determined. All data shown in this paper has been corrected for hole conditions assuming the hole is filled with seawater, the hole diameter is as measured by the cali- 


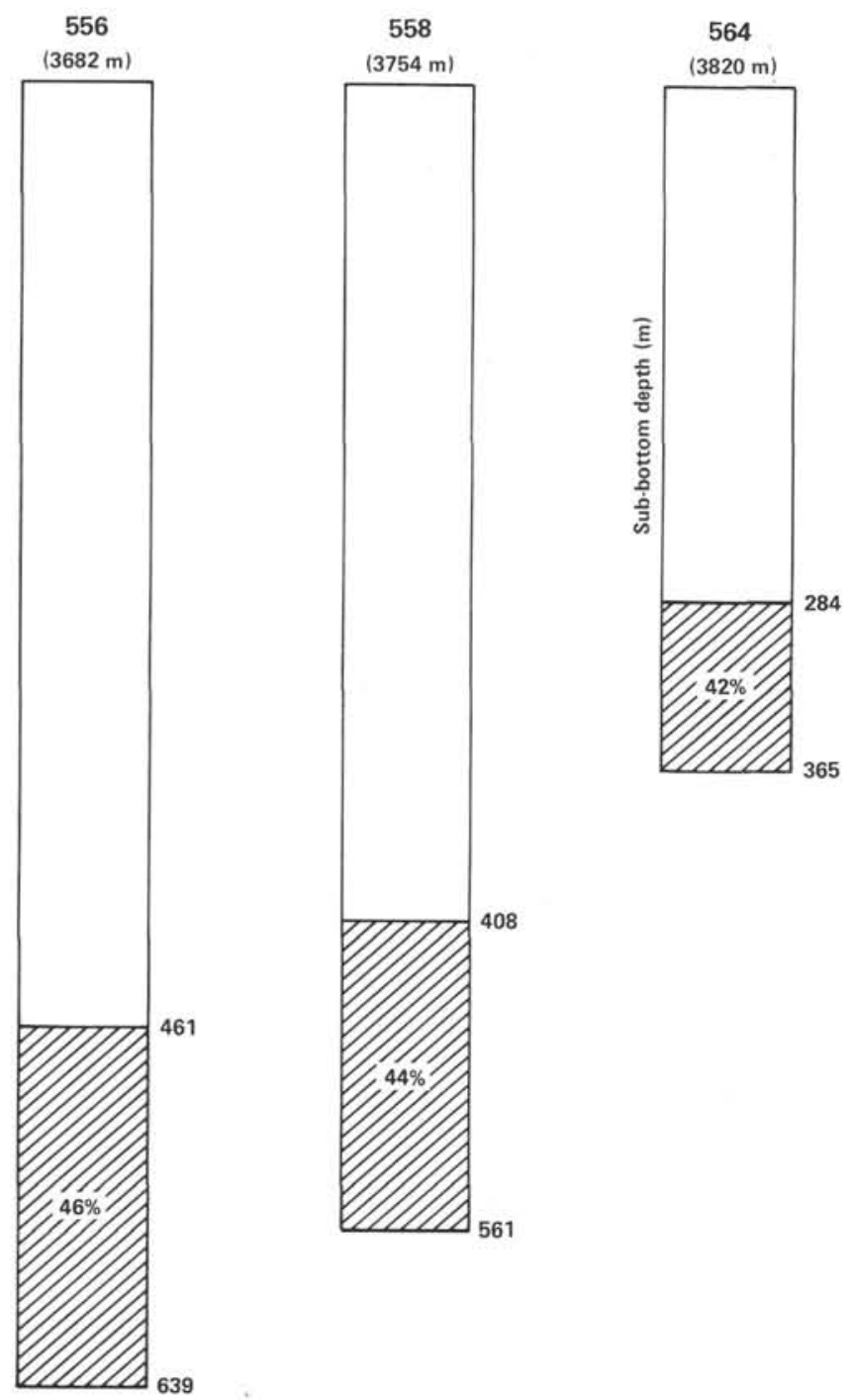

Figure 2. Sketch section of the formations drilled and logged at Holes 556,558 , and 564 . Water depth shown in parentheses. Sedimentary section blank, basement hatched. Basement interface and total depth shown in m sub-bottom. Percentage recovery of basement holes shown.

per, and the temperature is as measured by the temperature log (temperature variations are almost negligible) (Hill and Cande, this volume). Surface seawater properties were measured at each hole and applied to that hole, with all values similar (i.e., density, $1.06 \mathrm{~g} / \mathrm{cm}^{-3}$; resistivity, $0.21 \mathrm{ohm} \mathrm{m}$ at $20^{\circ} \mathrm{C}$, corrected to $0.30 \mathrm{ohm} \mathrm{m}$ at hole temperatures).

A ship-mounted rig presents the peculiar problem of heave. The drill string has a heave compensation mechanism to prevent the vertical motion of the ship from being transmitted to the drill bit. There was, however, no similar mechanism on board Glomar Challenger to decouple the logging wire from ship motion. In average deep-sea conditions, the vertical motion of the ship is slightly faster than the speed at which logging wire is heaved in during measurements. The tool therefore moves up the hole in an irregular manner. The logging tools are deliberately made to be heavy, several hundred pounds each, and the wire has very low elasticity. The tension in

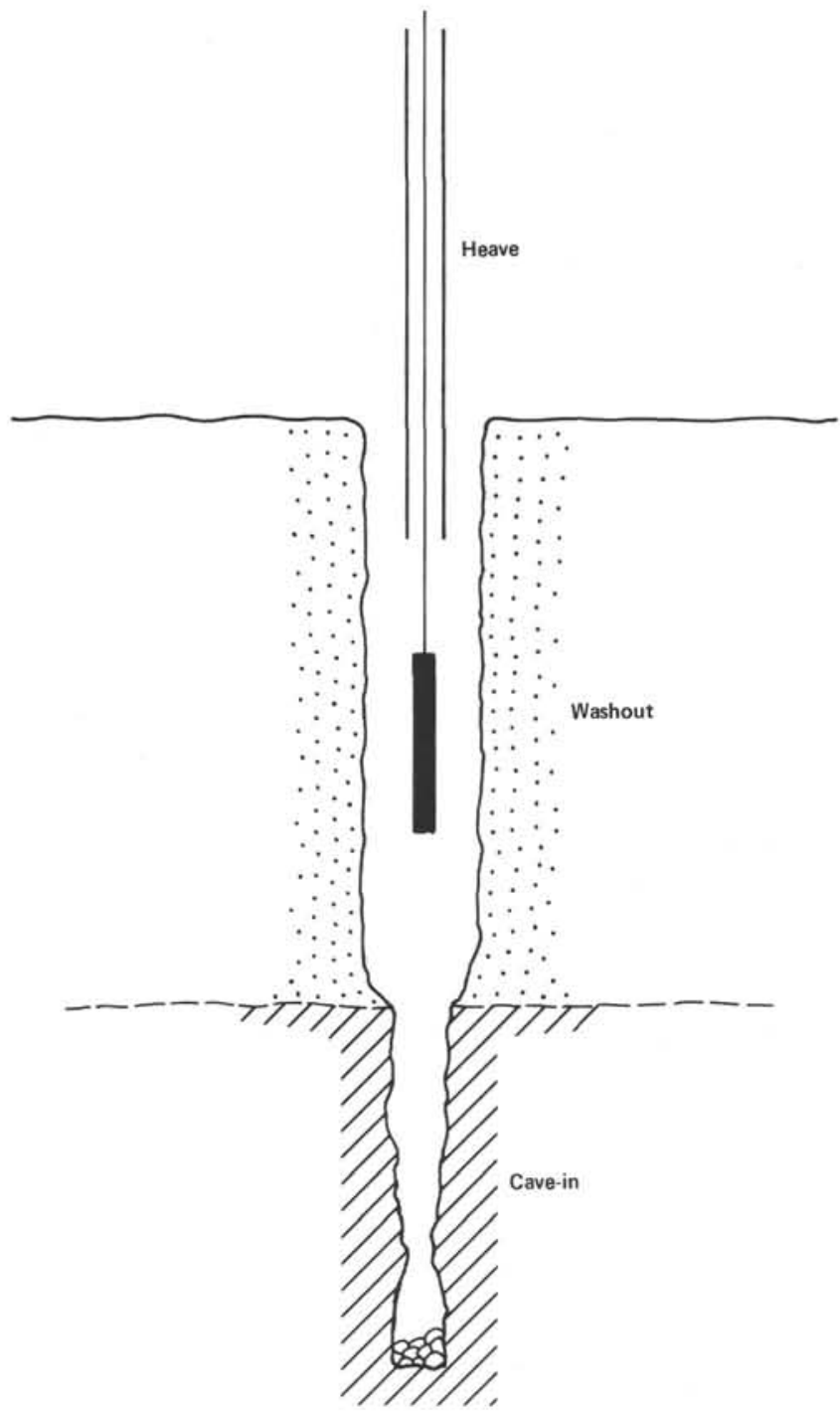

Figure 3. Diagrammatic section of a drilled hole showing conditions adversely affecting wireline logging. For discussion, see text.

the logging wire is continuously monitored and from the variations recorded, it appears that nearly all of the heave motion of the ship is transferred to the tool. Tests were conducted at Hole 564 where the resistivity tool was stopped at the basement/sediment interface and the heave motion in the wire moved the tool across the boundary so that the recorded values varied widely. This effect during normal logging inevitably results in uncertainty about the depth of any particular measurement. In addition, the tool may be in motion across any one lithologic boundary three times as it uscillates on its way up the hole. The Schlumberger Cyber Service Unit (CSU) logs data values at 6 -in. intervals of logging wire on recovery. For all interpretations and discussions in this report, the data values have been subject to a weighted averaging over 2 -ft. data intervals, after spurious noise values were deleted.

The suite of different logs is obtained by a sequence of three or four separate logging runs. On each of these a natural gamma-ray log is taken and used for depth correlation between different runs. The effect of the av- 
eraging procedure was monitored using this duplicate data and was found to improve correlation. Although differences can still arise, they do not inhibit correlation of the curves. Because the sediments have a uniformly low gamma-ray response, these differences are generally only evident in the basement section of the hole and may reflect more irregular motion of the tools against the rough (rugose) sidewalls.

For each hole the data from all log runs have been similarly treated and combined into one data file. This was done by using computer programs to read and edit the digitally recorded field data. Where duplicated log curves are available for gamma-ray and caliper measurements, the most complete and noise-free record was used in the final file. The complete suite of data thus comprises gamma-ray, caliper, density, neutron porosity, sonic transit time (inverse velocity), and deep and shallow laterolog resistivity. The principles and operation of the tools are well documented (Schlumberger, 1972) and will not be reviewed here. A summary of the particular tool types used in this work is given in Table 1.

\section{Laboratory Measurements}

The recovered cores were systematically sampled for measurement of sonic velocity, density, porosity, and thermal conductivity. All measurements were made using the standard equipment and techniques available on board Glomar Challenger and recommended by DSDP (Boyce, 1976). Details of individual sampling and measurement are included in the site chapters (this volume). Throughout the pelagic oozes and chalks, drilling disturbance was evident in the recovered cores, even in the cores recovered by hydraulic piston coring (HPC) although less disturbance was present than would have been expected from rotary coring. Because these least disturbed areas were selected, sampling for sonic velocity and density determination should have been as representative of undisturbed sediment as possible. Velocities for most of the oozes were measured through the plastic core liner, which adds considerably to the experimental error but cannot be avoided for very soft lithologies. Density and porosity were determined by 2-minute GRAPE and by gravimetric weighing, wherever possible on the same samples. The agreement of the two methods was good. Ther- mal conductivity measurements on soft lithologies were found to be little affected by drilling disturbance in the cores.

Cores from the sedimentary formations were measured with the continuous GRAPE method (Boyce, 1976) to provide a complete record of density variation with depth. Again, the data are subject to errors caused by drilling disturbance and void spaces within the core liner.

\section{Comparison of Downhole and Laboratory Data}

Site 558 provides an interesting comparison of the wireline density $\log$, the continuous GRAPE measurements, and sampled density measurements for the sedimentary formations (Fig. 5). All three methods record the same major features with a marked gradational increase in density at around $300 \mathrm{~m}$ sub-bottom and another increase at the very base of the sediment column. The density data from both laboratory sampling and continuous GRAPE also show values similar to those of the wireline log curve.

The comparison of laboratory and logged velocity measurements is not as good. Again both show the same gross features, but the laboratory values are systematically lower than the logged curves by up to $0.4 \mathrm{~km} / \mathrm{s}$. The seismic profile shows a two-way time for the basement reflector of $0.45 \pm 0.05 \mathrm{~s}$. A mean velocity of 1.8 $\pm 0.2 \mathrm{~km} / \mathrm{s}$ is required for the known depth of sediment. The error in this mean velocity is large because of the lack of definition of the basement reflector on the seismic profiler records. Although inconclusive, this mean velocity is more consistent with the logged in situ values than the laboratory values, which have no correction for the release of confining pressure and disturbance caused by core recovery. In these circumstances, there is no reason to doubt the accuracy of the logged curve values.

The thermal conductivity values, although not comparable to any logged data, do show a depth correlation with the other physical properties. The above consistency of the several data sets is a proof of the reliability and accuracy of the logging measurements in this particular application and lends confidence to the correlations of features between the logged curves for Holes 558, 556, and 564 and the sample measurements for Holes 558 and 563 .

Table 1. The tool types used for measurements on Leg 82 , the mnemonics for the data types recorded, and the approximate depth of investigation of the tool.

\begin{tabular}{|c|c|c|c|}
\hline $\begin{array}{l}\text { Measured } \\
\text { quantity }\end{array}$ & Tool type & $\begin{array}{c}\text { Curve } \\
\text { mnemonic } \\
\text { (units) }\end{array}$ & $\begin{array}{l}\text { Depth of } \\
\text { investigation } \\
\text { (m) }\end{array}$ \\
\hline $\begin{array}{l}\text { Diameter of } \\
\text { hole }\end{array}$ & Caliper & $\begin{array}{l}\text { CALI } \\
\text { (in.) }\end{array}$ & 0.0 \\
\hline $\begin{array}{l}\text { Natural } \\
\text { gamma }\end{array}$ & Formation gamma tool & $\begin{array}{l}\text { GR } \\
\text { (api) }\end{array}$ & $<1.0$ \\
\hline Sonic velocity & Depth derived borehole compensated (DDBHC) & $\begin{array}{c}\text { DT } \\
(\mu \mathrm{s} / \mathrm{ft} .)\end{array}$ & $<0.3$ \\
\hline Bulk density & Formation density compensated log (FDC) & $\begin{array}{l}\text { RHOB } \\
\left(\mathrm{g} / \mathrm{cm}^{3}\right)\end{array}$ & $<1.0$ \\
\hline $\begin{array}{l}\text { Neutron } \\
\text { porosity }\end{array}$ & Compensated neutron tool (CNT) & $\begin{array}{l}\text { NPHI } \\
(0-1.0)\end{array}$ & $<1.0$ \\
\hline $\begin{array}{l}\text { Formation } \\
\text { resistivity }\end{array}$ & $\begin{array}{l}\text { Laterolog dual spacing, termed deep and shallow, } \\
\text { only values from deep log are used here (DLL). }\end{array}$ & $\begin{array}{l}\text { LLD } \\
\text { (ohm m) }\end{array}$ & 4.0 \\
\hline
\end{tabular}




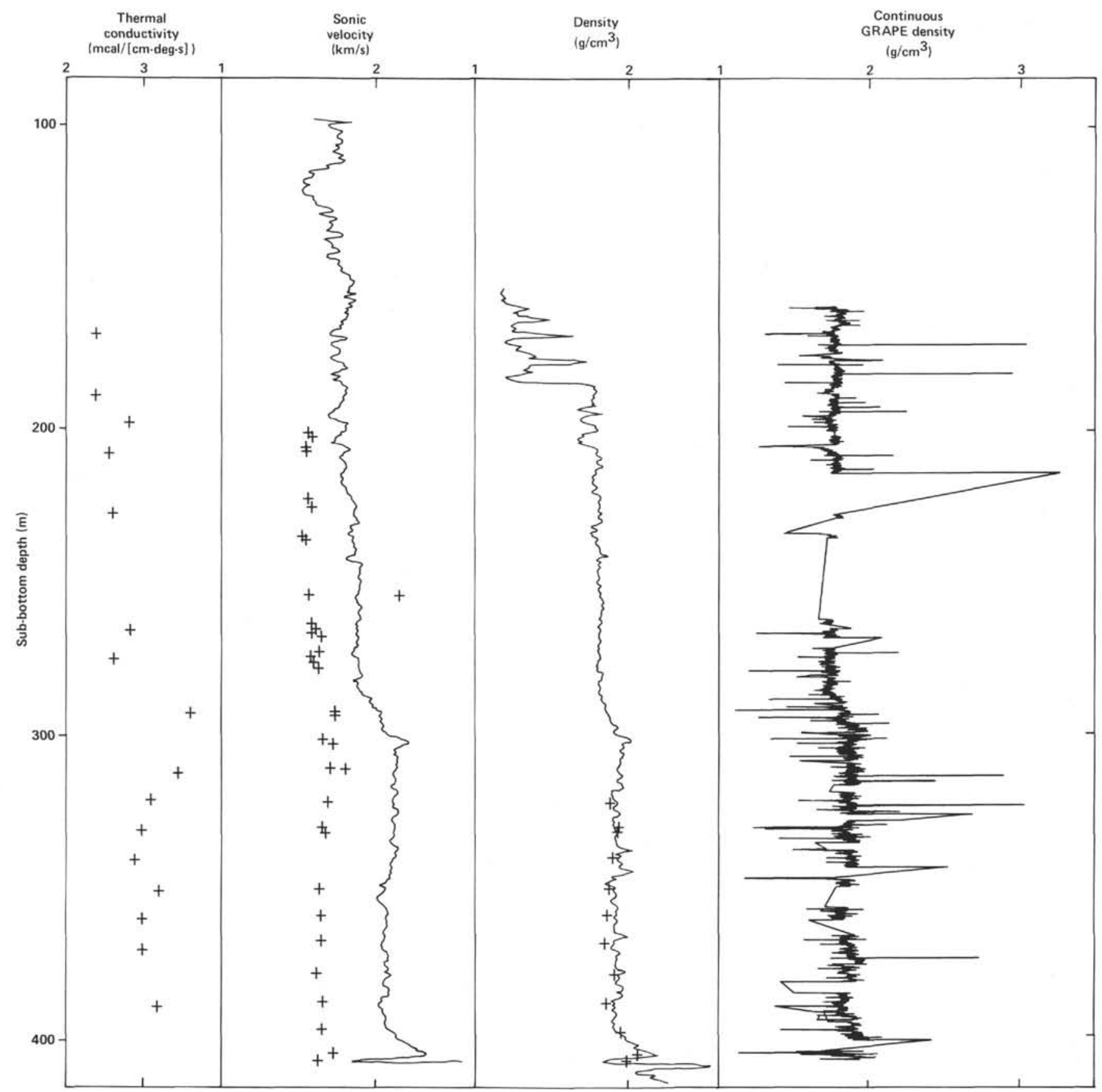

Figure 5. Comparison of laboratory and downhole physical property measurements for Hole 558. Thermal conductivity from sample measurement; sonic velocity from wireline logged curve (solid) and laboratory samples (crosses); density from wireline logged curve (solid), and individual sample measurements (crosses); density measurements from the continuous GRAPE.

For measurements within the basement formations, there is no such simple assessment of accuracy and reliability. The recovered core comprises the more physically resistant $44 \%$ of the drilled formation and the logging tools sample a more complete section, so that laboratory measurements probably represent the maximum likely values for the bulk properties of density, velocity, and resistivity, and the minimum value for porosity. The degree to which the log curves approach these values depends on the relative scales of the measured volume sampled by the logging tool and the wavelength of property variations within the formations. The sidewall penetration of the tools is shown in Table 1, but the effect of the tool motion because of ship's heave and the subsequent averaging in the data processing increases the effective sample volume. Thus, it is difficult to compare the laboratory and logged data sets and assess the accuracy of the logged curves independently. This problem is particularly acute for resistivity measurements where the bulk property is highly dependent on fracturing, which can never be represented in a laboratory sample. In the absence of such comparisons, the logged values will be 
assumed reliable, but the question of accuracy will be reassessed after the discussion of the data set below.

\section{CORRELATION OF THE SEDIMENT MEASUREMENTS AND GEOLOGIC INTERPRETATION}

The results from Hole 558 allow correlation between geologic observations on core material and logged curves. Figure 6 shows the sonic velocity curves through sediment formations and their correlation between holes, with core descriptions from Holes 558 and 563. The data can be examined on a larger scale in Figure 4 (back pocket).

The most prominent correlation from all the holes is the marked change in lithology and physical properties a little below the center of the stratigraphic column. This can be seen on all logged curves for density, velocity, and rather less prominently, resistivity. It is apparent on the laboratory physical properties at Holes 558 and 563 site chapters, Sites 558 and 563, this volume) and also in the sedimentologic core logs for these holes. The change is primarily due to a sharp increase in the clay content of the sediments below the boundary, which is placed at $300 \mathrm{~m}$ sub-bottom in Hole 558 from the sediment analy-

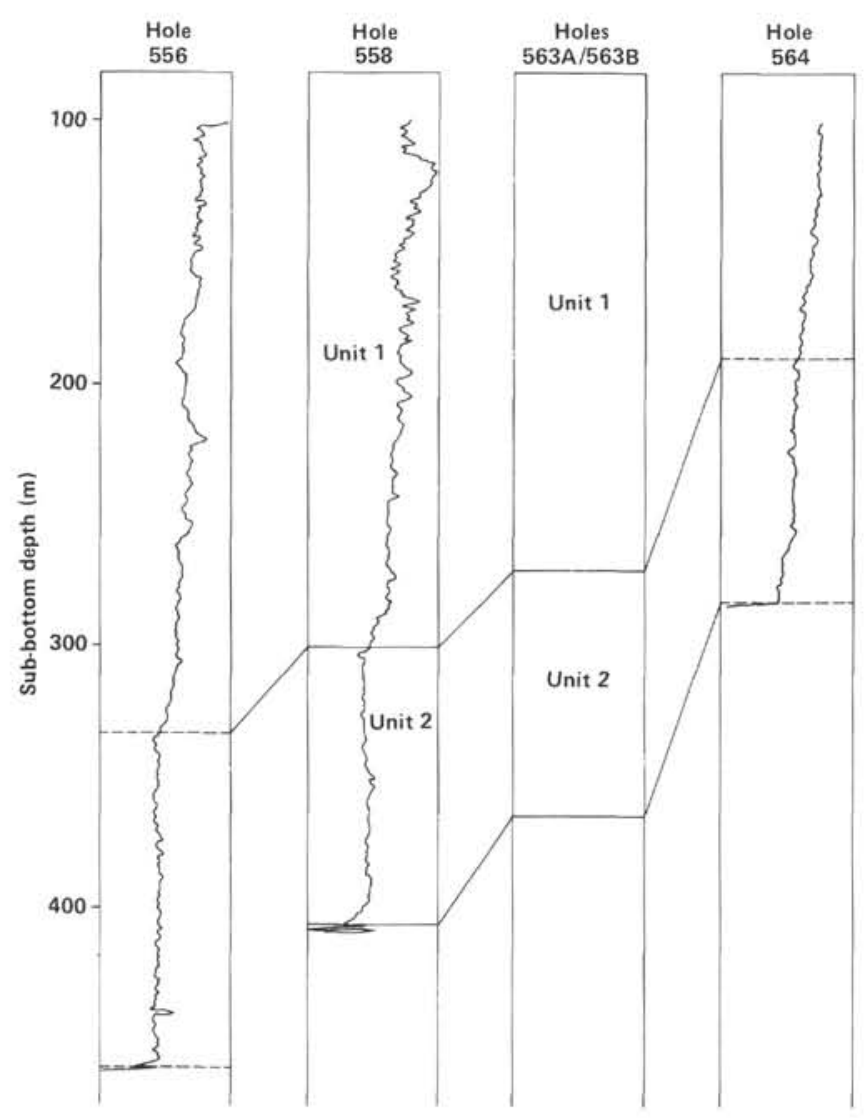

Figure 6. Correlation of logged sonic velocity curves for sediments at each hole with core descriptions for Holes 556, 558, 563A/563B, and 564 (velocity plotted as sonic transit time scaled as 0-200 $\mu \mathrm{s}$ / ft. from left to right, i.e., velocity increases to left of plots). Dashed lines are correlations based on the log curves. Units shown are lithologic units. sis. Although the sediment composition changes sharply at this depth (site chapter, Site 558, this volume), the physical property change is more gradual. The wireline logs are almost constant below $300 \mathrm{~m}$ sub-bottom, whereas above this level, there is a steady gradient in properties presumably because of compaction. In the $20 \mathrm{~m}$ immediately above the boundary, the gradient in physical properties is more marked but still relatively smooth, whereas the sediment composition appears to show sharp variations in the clay content within this region. It is quite likely that the sediment composition variations are on such a sufficiently short depth scale that the effects are averaged by the logging tools to produce the overall gradient. The sediment analyses are not closely enough spaced to accurately define the wavelength of these compositional variations. At $303 \mathrm{~m}$ sub-bottom, there is a prominent increase in seismic velocity, increase in resistivity, and increase in density over an interval of $4 \mathrm{~m}$. This is, however, an artifact of the logging tools produced by the washout in the hole walls at that depth revealed by the caliper log. Most of the minor variations in logged values superimposed on the trends noted above probably are noise created by the irregular sidewalls and have no geologic significance.

The logged curves for Hole 556 show a very clear correlation with those for Hole 558. All the major features described above can be easily identified at Hole 556 with the major lithologic change occurring at $336 \mathrm{~m}$ sub-bottom, $125 \mathrm{~m}$ above basement compared with the $103 \mathrm{~m}$ above basement at Hole 558. The data from Hole 556 also has the same sources of noise as that discussed above for Hole 558. In particular, the density and neutron porosity values are very noisy because of intermittent sidewall contact. The reason for this is not obvious because the longer-reach sonic log caliper shows that the mean diameter of the sedimentary section of Hole 556 is less than that of Hole 558, leading to an expectation of poorer sidewall contact for the nuclear logs in Hole 558. Despite this unexplained anomaly, the modal values for the densities over depth intervals correlated from the sonic logs are the same for both holes, lending confidence to the correlation. It is a reasonable inference that the lithologies within the sediment column at Hole 556 are very similar to those at Hole 558, implying similar depositional histories throughout the duration of sedimentation.

The situation at Hole 564 is slightly less clear because of the shorter length of the logged interval and the lower gradients in physical property changes. The sonic velocity curve shows four separate depth intervals. For the lowest, $30 \mathrm{~m}$ above basement, there is a marked gradient of increasing velocity. Above this for $60 \mathrm{~m}$ the velocity is constant, whereas above $195 \mathrm{~m}$ sub-bottom the velocity decreases again, then levels off to a lower gradient above $130 \mathrm{~m}$ sub-bottom. This pattern is shown weakly by the resistivity curve with two intervals of almost constant value, a low gradient between them, and a more marked increase towards basement. The density curve also shows these features. The depth intervals so defined and the relative changes in properties can be correlated with those for Hole 558, and the geologic interpretation of that 
hole extended to the area of Hole 564. The confidence in this correlation is greatly increased by the knowledge of the core logging from Hole 563, very close to Hole 564. At Hole 563, the sedimentary column was divided into two units that correlate with those at Hole 558 (the lower unit is about $90 \mathrm{~m}$ thick). From the sediment analysis at Hole 563, the lower unit again has an increase in clay content, but only to $15 \%$ rather than the $50 \%$ clay content at Hole 558.
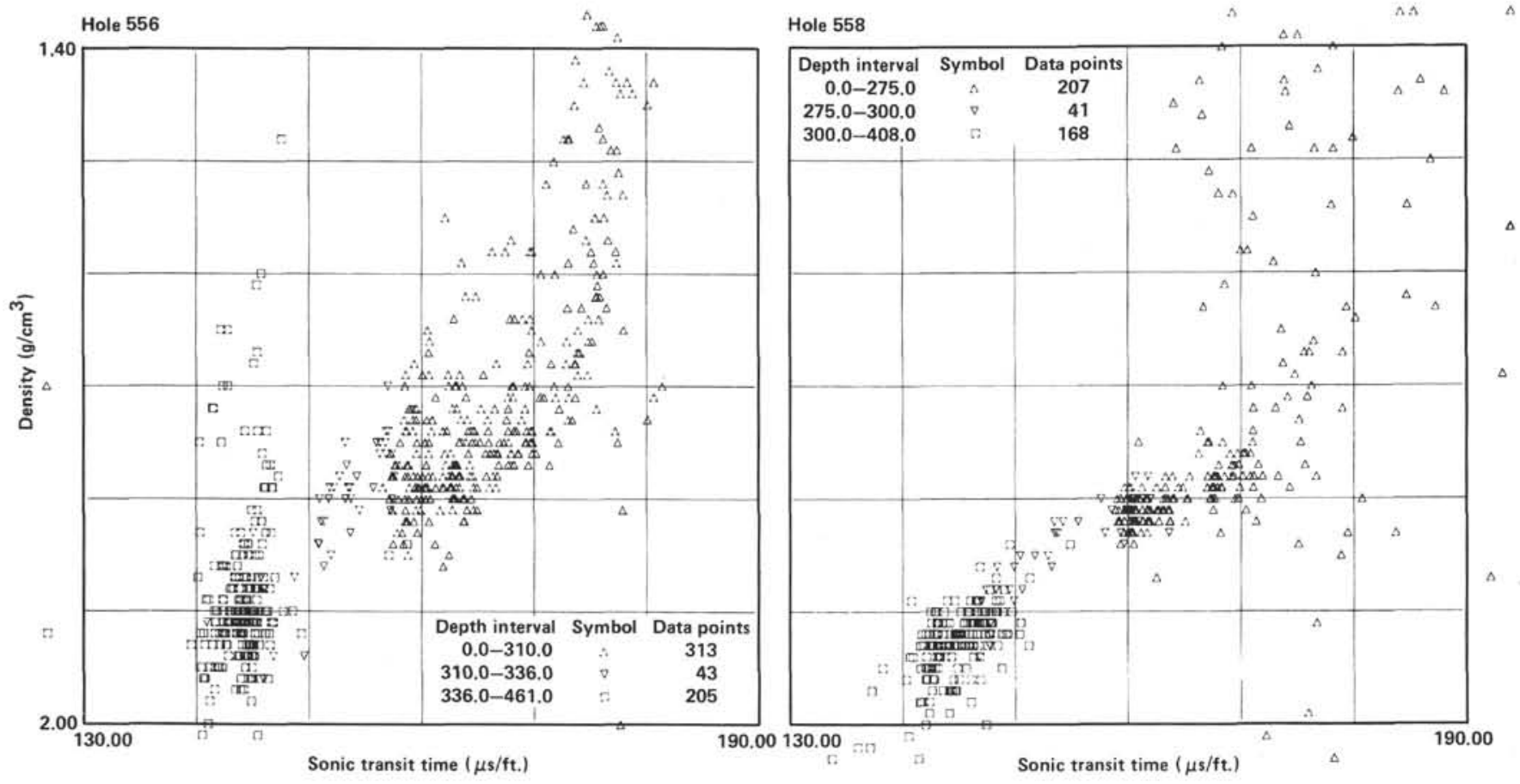

The recognition of these two distinct lithologic units at each hole from the logged curves can be shown by the crossplots in Figure 7. Here the value at each depth interval is plotted in a field where position depends on the values of two of the logged values at that depth. The two curves with the most variations are the sonic velocity and density, and the crossplots of these values clearly show the division of the sedimentary sequence into two units for each hole.

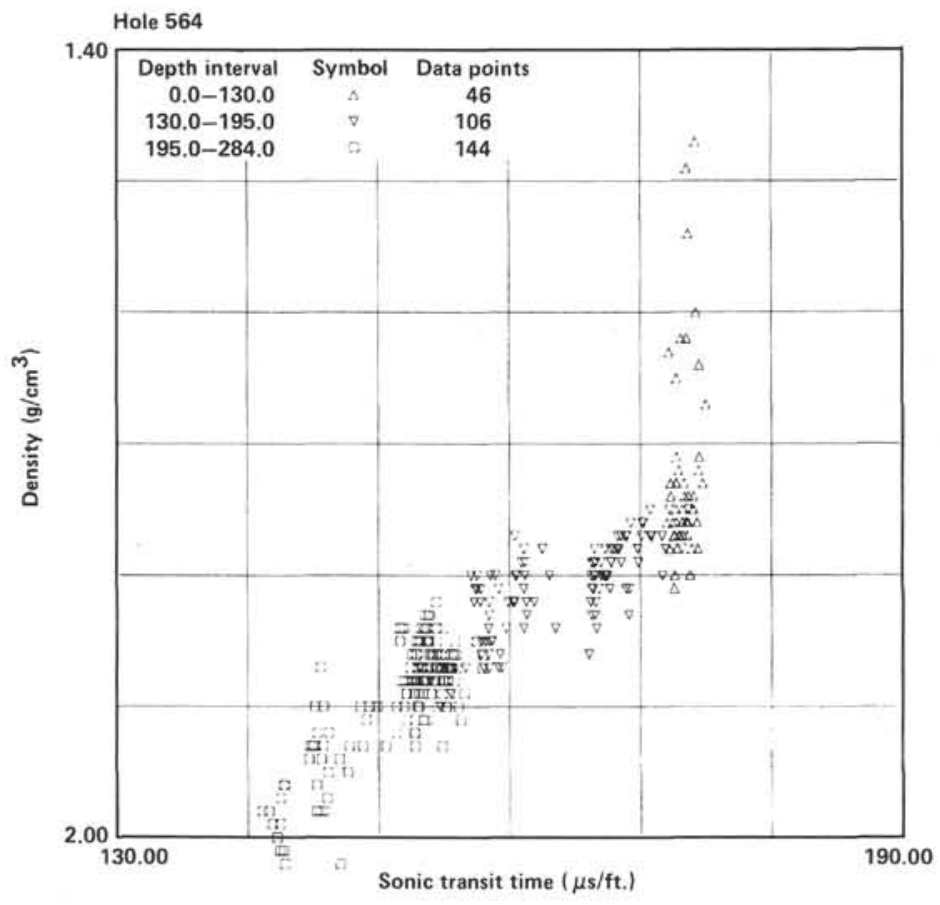

Figure 7. Density-sonic cross plots for the sedimentary formations of Holes 556, 558, and 564. Vertical data interval is $2.00 \mathrm{ft}$. 
The logging results from the sedimentary columns in Holes 556, 558, and 564 thus allow correlation of sedimentary units between all holes. This has an important bearing on the interpretation of the depositional history at Hole 558 as found in detail from the core logging because it can now be seen as truly representative of a large geographic area and not a result of local effects.

\section{LOGGING MEASUREMENTS IN IGNEOUS BASEMENT}

The ocean basement constitutes a difficult environment for wireline logging because of the lateral and vertical inhomogeneity of the formations. Because this inhomogeneity often occurs on scales smaller than the sampling volume of the logging tool, the log curves often show a smoothed record of the variations in the formation. Nevertheless, continuous logged curves from this region are highly desirable because of the incomplete and biased nature of the recovered core. The problems of assessing the accuracy of the logged curve values has been discussed above. This report will consider the interpretation of the curves: first, with respect to the identification of major lithologic features and, second, with regard to the variation of properties of the igneous rocks.

\section{Lithologic Units}

The log curves were initially interpreted on board ship and the basement divided into a number of units as described in the site reports (this volume). This initial division was performed purely on the appearance of the curves from each individual hole. This process can now be repeated within the perspective of the curves for all holes and the units defined by core description and chemical analyses. The curves filtered as described above are shown in Figures 4A, 4B, and 4C (back pocket). The data for each hole will be described in turn.

Hole 556 had the most successful logging operations and hence has the most complete data set within the basement. The basement surface is prominently shown at $461 \mathrm{~m}$ sub-bottom by sharp deflections of all curves. Below this, the curve variations are more complex. Between 461 and $560 \mathrm{~m}$ sub-bottom, there is a gradual rise and then fall of resistivity values with a series of much shorter wavelength variations superimposed. On the lithologic log, this interval appears to be mainly pillow basalts. Such a response is to be expected with short wavelength variations because of the location of pillow margins and brecciated zones, which are somewhat smoothed out by the averaging effect of the resistivity tool. The longer wavelength variation must be due to more systematic processes. The upper surface of this unit must have had prolonged exposure to seabed weathering effects before being buried by sediment. Such alteration could produce the observed change in resistivity, but this simple explanation is unlikely to be true because recovered core material shows no systematic variation in alteration throughout this interval nor a change in percentage core recovery that might imply the same effect. The decreasing resistivity towards the surface may reflect increasing fracturing. The decrease towards the base of this unit may have a similar origin.
Below $560 \mathrm{~m}$ sub-bottom, the major lithology changes to altered gabbro. Between 560 and $577 \mathrm{~m}$ sub-bottom, there is a zone of particularly low resistivity that correlates with a high apparent porosity shown by the neutron porosity curve. The major serpentinization of recovered cores reveals that a great deal of seawater alteration has occurred at this level, and this alteration may have also affected the pillow lava unit, contributing to the long wavelength decrease in resistivity noted above. At $577 \mathrm{~m}$ sub-bottom there is a marked increase in resistivity, and density, but, because this is not revealed as a major change in the lithologic log, it can be attributed to a decrease in the alteration or, more probably, a decrease in the fracturing of the gabbros. Resistivity changes sharply downwards at $611 \mathrm{~m}$ sub-bottom to values of about $10 \mathrm{ohm} \mathrm{m}$, which may again be interpreted as an increase in alteration and/or fracturing. The major boundaries noted above can be seen to correlate to features on other curves in Figure 4B (back pocket) as well as to the resistivity. The resistivity curve has been used as a basis of discussion because of the large volumetric averaging of this tool that smooths out the small-scale heterogeneity of the basement formations on a scale of less than $1 \mathrm{~m}$ and shows the systematic trends more clearly. More detailed resistivity investigations in Hole 504B (Becker, Von Herzen, et al., 1982) have demonstrated the usefulness of resistivity measurements in differentiating major lithologic units and support the correlation of resistivity variations primarily with fracturing. It is interesting that the Hole 504B data have mean resistivity values in the pillow lavas of Layer 2 of only $10 \mathrm{ohm} \mathrm{m}$. The values from the Leg 82 data are higher by up to a factor of 10 and are also higher than equivalent data from Hole 417D. As discussed below, absolute calibration of resistivity tools is hard to verify and it remains to be determined whether differences are due to calibration errors, the variations in the effective volumes sampled by the different tools used for each set of measurements, or the true variations in the bulk properties of the wall rocks.

The curves for Hole 558 are less complete with the loss of density and neutron porosity data for much of the basement section because of hole cave-in. The basement surface is clearly seen at $408 \mathrm{~m}$ sub-bottom, but the sharp increase in resistivity occurs at $405 \mathrm{~m}$ sub-bottom. Possibly this effect originates from a depth error on the resistivity curve, but this is unlikely because all curves were depth correlated using the gamma-ray curves as was done for all other holes, and the change in resistivity and sonic velocity at $520 \mathrm{~m}$ sub-bottom shows no similar depth error. Therefore, the resistivity increase between 405 and $408 \mathrm{~m}$ sub-bottom is real and, as such, can be explained by an increase in cementation. This would increase resistivity while leaving density and sonic velocity relatively unaffected. This is likely because a marked increase in dolomitization was noted in the bottom few meters of sediments from the recovered cores. Apart from the boundaries noted above, there are no other major interfaces revealed by logging. This is not surprising because the lithologic log shows a continuous pillow basalt sequence to $520 \mathrm{~m}$ sub-bottom, underlain by altered gabbros. 
Shorter wavelength variations are superimposed on these major units as was noted for Hole 556. In particular, there are a number of zones of lower resistivity and related lower seismic velocity within the pillow lava unit. The most prominent of these zones is that between 423 and $440 \mathrm{~m}$ sub-bottom, which is also defined by the density and neutron porosity curves. The logged values would suggest a region of increased porosity and, possibly, fracturing.

Hole 564 presented the same difficulties to logging as Hole 558 did, and the data are similarly incomplete. Once again the basement surface is apparent, but no other major features are seen. Yet porosity and density variations within the pillow lava sequence close below the basement surface coincide with a zone where water inflow is inferred by thermal data (Hill and Cande, this volume). The increase in neutron porosity and decrease in density with little effect on the sonic velocity could imply that the formation is vesicular or subject to microfractures rather than uniformly porous, with seismic ray paths available that can avoid small voids or fractures and hence leave the sonic velocity unaffected.

\section{ACCURACY OF PHYSICAL PROPERTIES}

The local heterogeneity of the basement formations is averaged to some extent by all logging tools. The bulk properties data recorded in the curves cannot be verified because there is no independent measures of similar quantities. Recovered cores will preferentially sample the harder lithologies, which withstand the drilling and recovery process better. The only check is to verify that the range of bulk properties is compatible with an average of the measured sample properties, taken in the correct proportions by volume.

Resistivity values can be subject to many effects of the hole diameter and borehole fluid salinity. The laterolog tool used here has electrode arrays to make resistivity measurements at two depths of penetration of the borehole walls, typically on the order of 1 and $4 \mathrm{~m}$. Both values are corrected for estimated effects of hole diameter and fluid salinity, and the results have been compared. The deeper measurement gives values that are systematically higher than the shallow measurement by up to a factor of ten within basement lithologies. The shallow measurement is more affected by the hole fluid and the deep measurement has been taken as the more accurate value. These values are an average of about $300 \mathrm{ohm} \mathrm{m}$ for pillow basalt formations with variations between 1000 and $100 \mathrm{ohm} \mathrm{m}$, whereas gabbros give lower values of about $10 \mathrm{ohm} \mathrm{m}$, but up to $100 \mathrm{ohm} \mathrm{m}$ in one section of Hole 556. These maximum values are quite reasonable for igneous rocks with very low porosity; cored basalt samples have porosity as low as $2 \%$. The lower values are due to averaging with interpillow breccia and void spaces. The altered gabbros would be expected to be systematically lower because of their increased porosity on alteration and the conductive nature of some of the alteration products. It is concluded that the measured values are quite plausible, if not strictly calibrated.

The consideration of sonic velocities follows a very similar line to that for resistivities. The logged curves have maximum values that agree quite well with the values measured on laboratory samples. Variations in the logged curves are generally smoother because of the considerable depth interval sampled by the tool, about $3 \mathrm{~m}$. Intermittent spurious values are generated by physical shocks to the tool that are detected as spurious arrivals of sonic waves.

The density and neutron porosity tools have particular problems because of their use in sidewall contact measurements. Rugosity of the sidewall on a short wavelength prevents good sidewall contact and causes anomalously low density and high porosity values. In many cases there is a correlation between short-wavelength, high-amplitude variations on these logs and wall rugosity detected by the caliper log. Despite these problems, the maximum densities are similar to those determined from the samples. Neutron porosity values are systematically higher than porosities determined by sample measurements. The major cause of this is the highly fractured and jointed nature of the formations with these fractures contributing to the bulk porosity. Within the gabbro formations, and to a lesser extent in the altered basalts, the alteration products contain bound water that will be detected by the neutron log as a component of the total porosity.

The caliper log is not susceptible to errors such as those described above and is undoubtedly accurate. The gamma-ray curves can only be assessed by their repeatability because a separate curve is obtained with each logging run. The repeatability was found to be very good within the limitations set by tool heave as described earlier. There is no discernible correlation between the very low-level gamma radiation levels of the basement formations and lithologies.

\section{COMPARISON WITH HOLE 417D RESULTS}

The only other data for similar logging experiments available for identical analysis at the present are from Hole 417D. This hole in Atlantic crust (aged $108 \mathrm{Ma}$ ) was logged with partial success after many technical failures to give the data curves shown in Figure 4D (back pocket) and previously described by Salisbury et al. (1980). The basement surface is seen at a depth below sea level of $5823 \mathrm{~m}$, and below this curve values for a formation of pillow lavas are broadly comparable to those of Leg 82. Particularly different features are the smoother nature of the curves and the generally lower values of resistivity. Whereas the former effect is likely to be a feature of the geology, the latter could well be an effect of the different type of resistivity tool used for the 417D measurements, the Laterolog 8. Resolution of this problem requires detailed investigation of the response of each tool in this environment and has not been completed. The sonic velocities are broadly comparable, but those for Hole 417D are more uniform in nature, which may well reflect infilling of fractures and void spaces by alteration products with age.

No density or neutron porosity data are available for Hole 417D except over the interval between 343 and $369 \mathrm{~m}$ sub-bottom. This limited sampling makes difficult any meaningful comparison with the results from Leg 82 on younger crust. The large range of logging experiments 
now completed in Hole 504B establish it as a reference for comparison of all other data, and such comparison has been made where relevant within the text.

\section{CONCLUSIONS}

Logging operations were particularly successful on Leg 82 and yielded good quality data. The sedimentary column contains little lithologic variation, but those minor variations present and identifiable by the downhole measurements can be reliably correlated between holes using the logged curves. The basement logging has clearly differentiated between pillow lavas and gabbros and reveals the presence of distinct zones of high degrees of alteration and high porosity and fracturing. Thin zones with poor core recovery can be assigned a more accurate depth extent from the logged curves than from the recovered core.

It is clear that logging operations are a very useful addition to the DSDP capability, but require more extensive use in drilled holes of greater depth before the data can be reliably interpreted in terms of the aging structure of ocean crust.

\section{ACKNOWLEDGMENTS}

We would like to thank the Captain and crew of the Glomar Challenger and especially Glen Foss and the Schlumberger engineer, Ed Moffat, for their work in collecting this data.

\section{REFERENCES}

Anderson, R. L., Honnorez, J., Becker, K., Adamson, A. C., Alt, J. C., Emmerman, R., Kempton, P. D., Kinoshita, H., Laverne, C., Mottl, M. J., and Newark, R. L., 1982. DSDP Hole 504, the first reference section over $1 \mathrm{~km}$ through Layer 2 of the oceanic crust. Nature, 300:589-594.
Becker, K., Von Herzen, R. P., Francis, T. J. G., Anderson, R. N., Honnorez, J., Adamson, A. C., Alt, J. C., Emmerman, R., Kempton, P. D., Kinoshita, H., Laverne, C., Mottl, M. J., and Newark, R. L., 1982. In situ electrical resistivity and bulk porosity of the oceanic crust, Costa Rica Rift. Nature, 300:594-598.

Boyce, R. E., 1976. Definitions and laboratory techniques of compressional sound velocity parameters and wet-water content, wetbulk density, and porosity parameters by gravimetric and gamma ray attenuation techniques. In Schlanger, S. O., Jackson, E. D., et al., Init. Repts. DSDP, 33: Washington (U.S. Govt. Printing Office), 931-956.

1981. Electrical resistivity, sound velocity, thermal conductivity, density-porosity, and temperature, obtained by laboratory techniques and well logs: Site 462 in the Nauru Basin of the Pacific Ocean. In Larson, R. L., Schlanger, S. O., et al., Init. Repts. $D S D P, 61$ : Washington (U.S. Govt. Printing Office), 743-762.

Cann, J. R., and Von Herzen, R. P., 1983. Downhole logging at Deep Sea Drilling Project Sites 501, 504, and 505, near the Costa Rica Rift. In Cann, J. R., Langseth, M. G. Honnorez, J., Von Herzen, R. P., White, S. M., et al., Init. Repts. DSDP, 69: Washington (U.S. Govt. Printing Office), 281-300.

Kirkpatrick, R. J., 1978. Results of downhole geophysical logging Hole 396B, DSDP Leg 46. In Dmietriev, L., Heirtzler, J., et al., Init. Repts. DSDP, 46: Washington (U.S. Govt. Printing Office), 401-407.

Salisbury, M. H., 1983. Basement logs from the mouth of the Gulf of California, Deep Sea Drilling Project Leg 65. In Lewis, B. T. R. Robinson, P., et al., Init. Repts. DSDP, 65: Washington (U.S. Govt. Printing Office), 329-342.

Salisbury, M. H., Donnelly, T. W., and Francheteau, J., 1980. Geophysical logging in Deep Sea Drilling Project Hole 417D. In Donnelly, T., Francheteau, J., Bryan, W., Robinson, P., Flower, M., Salisbury, M. H., et al., Init. Repts. DSDP, 51, 52, 53, Pt. 1: Washington (U.S. Govt. Printing Office), 705-714.

Schlumberger, 1974. Schlumberger Log Interpretation. Vol 1: Principles: New York (Schlumberger Ltd.)

Date of Initial Receipt: 2 December 1983

Date of Acceptance: 12 January 1984 